\title{
Publisher Correction: A practical guide to placental examination for forensic pathologists
}

\author{
Namita Mittal $^{1} \cdot$ Roger W. Byard ${ }^{2,3}$ (D) Jane E. Dahlstrom ${ }^{1,4}$ (D)
}

Published online: 8 January 2020

(C) Springer Science+Business Media, LLC, part of Springer Nature 2020

Publisher Correction: Forensic Science, Medicine and Pathology https://doi.org/10.1007/s12024-019-00214-2

The Publisher would like to correct the introduced formatting errors caused by production on figures 16 and 23 of the original article. The errors are purely typesetting mistakes and the corrections made to the figures did not impact upon the veracity and content of the overall text of the article in any way.

1) In Figure 16, panel $d$ was not captured in the final version.

2) In Figure 23, panel c was not captured in the final version.

The Publisher apologizes for the oversight and for any confusion it may have caused.

The online version of the original article can be found at https://doi.org/ 10.1007/s12024-019-00214-2

Jane E. Dahlstrom

jane.dahlstrom@act.gov.au

1 Anatomical Pathology, ACT Pathology, The Canberra Hospital, Canberra Health Services PO Box 11, Woden, ACT 2606, Australia

2 Faculty of Medicine, University of Adelaide, Frome Rd, Adelaide 5005, Australia

3 Forensic Science SA, GPO Box 2790, Adelaide 5001, Australia

4 College of Health and Medicine, Australian National University Medical School, Canberra, ACT 2601, Australia 
The original article has been corrected and the updated figures are shown below.
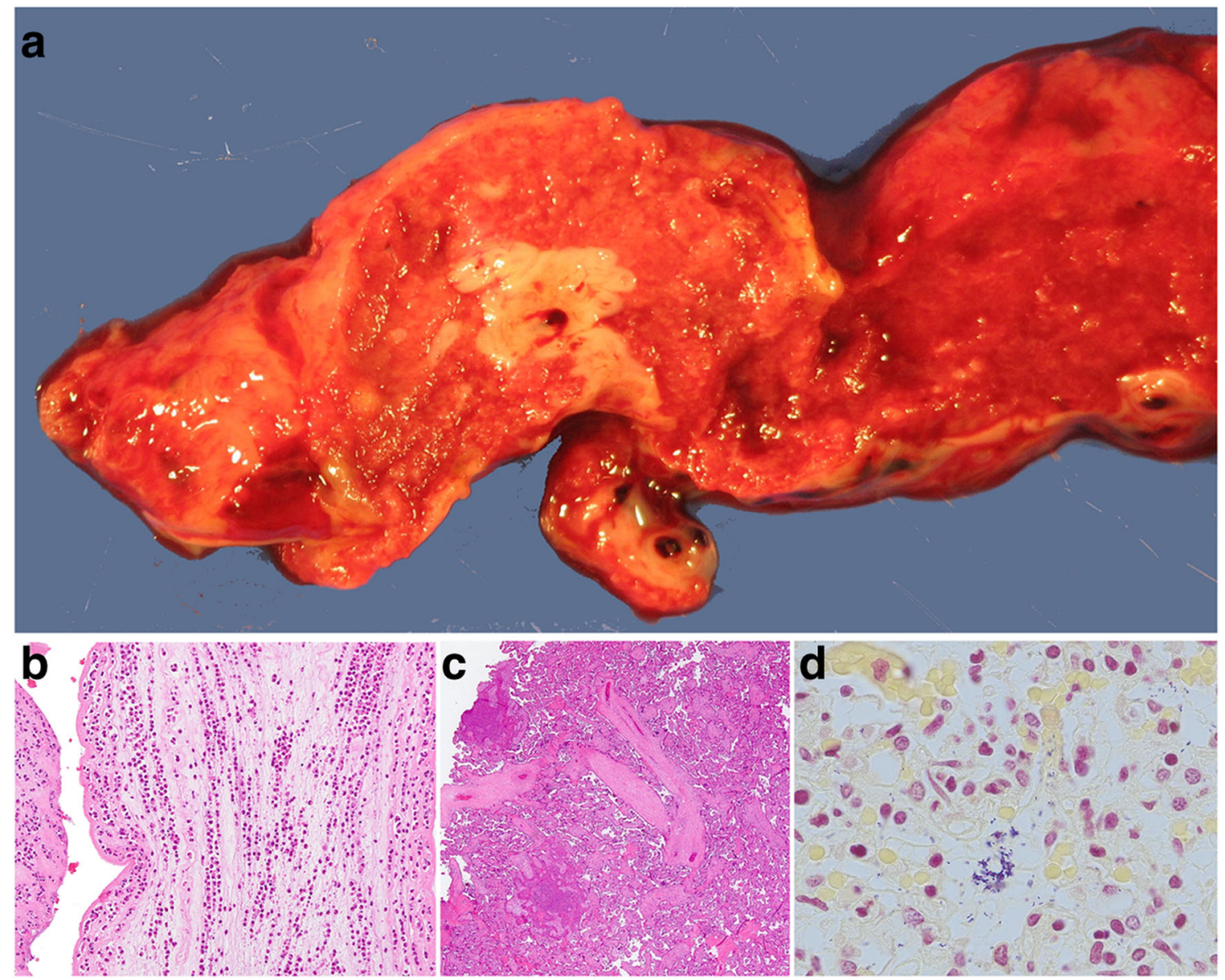

Fig. 16 Listeria monocytogenes. Mother presented at 30 weeks gestation with a fever of $38^{\circ} \mathrm{C}$. a Multiple abscesses evident within the placental parenchyma. b Acute chorioamnionitis (maternal inflammatory response grade 2, stage 3 ) (H\&E, Original magnification $\times 200)$. c Two microabscesses (black arrows) at low power (H\&E, Original magnification $\times 50)$ and high power $(\mathrm{H} \& \mathrm{E}$, Original magnification $\times 400$ ). d Gram stain demonstrated gram positive bacilli in the intervillous space and membranes $(\mathrm{H} \& \mathrm{E}$, Original magnification $\times 1000)$ 


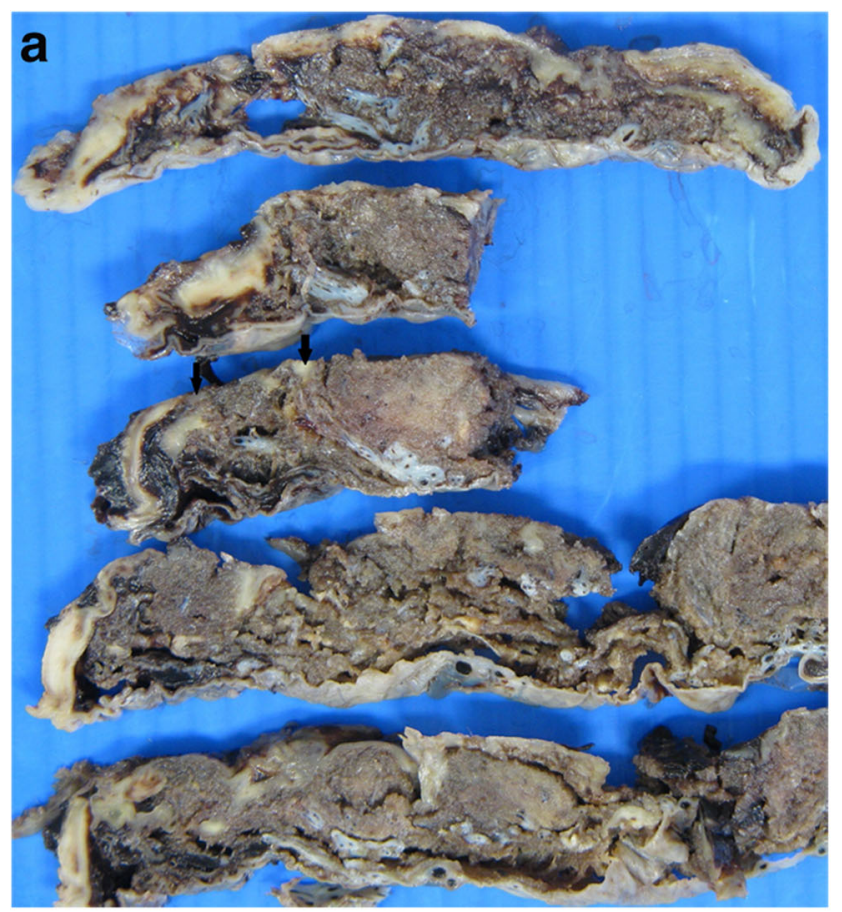

Fig. 23 Diffuse large B cell lymphoma in a placenta delivered at 32 weeks. The placental disc weighed $450 \mathrm{~g}$. Coiling index $1 \mathrm{coil} / 5 \mathrm{~cm}$. a Ill-defined cream nodules less than $15 \mathrm{~mm}$ across on the basal plate aspect of the disc of varying size. $\mathbf{b}$ Infiltrate of large atypical cells within fibrin $(H \& E$, Original magnification $\times 400)$ c $(C D 20$ [L26] immunostain, Ventana, mouse monoclonal, 1/100 dilution, Original magnification $\times 200$ )
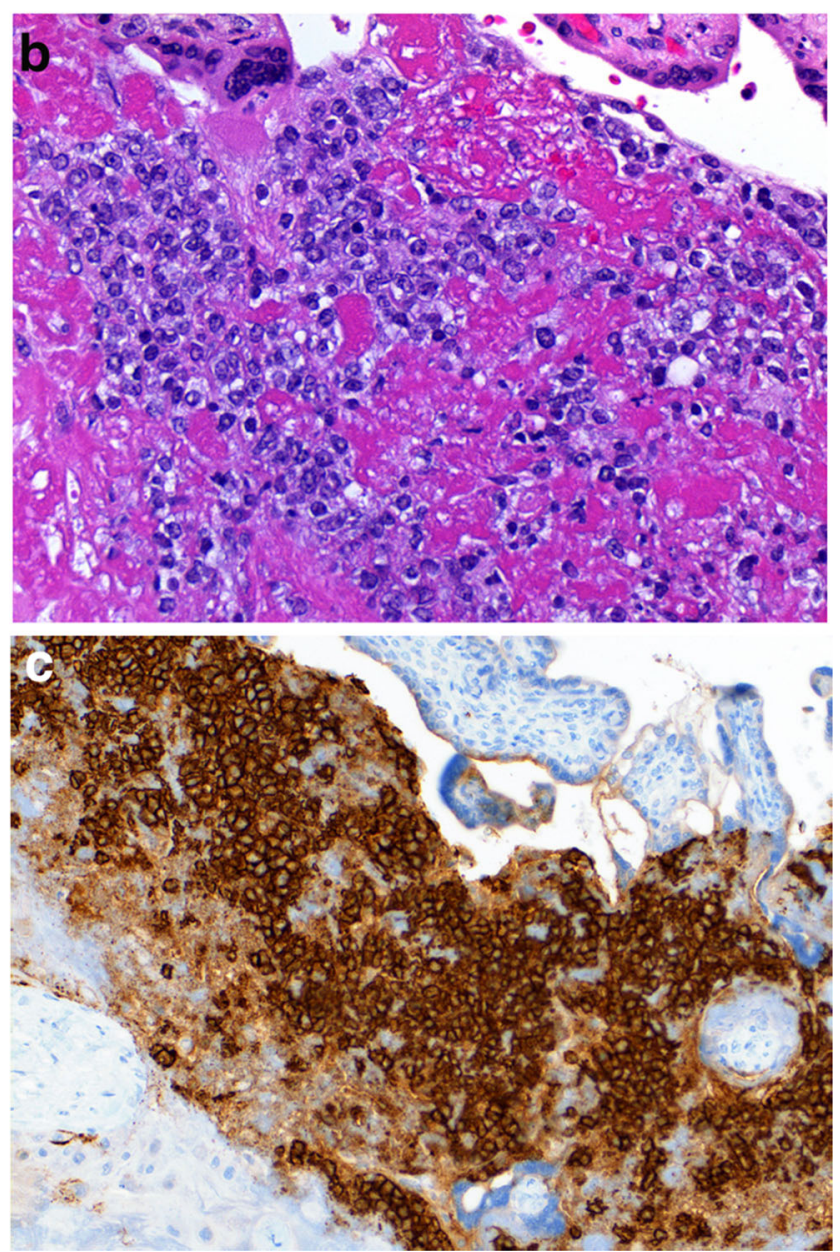